\title{
Gut microbiota, the immune system, and diet influence the neonatal gut-brain axis
}

\author{
Michael P. Sherman ${ }^{1}$, Habib Zaghouani ${ }^{1,2,3}$ and Victoria Niklas ${ }^{4}$
}

The conceptual framework for a gut-brain axis has existed for decades. The Human Microbiome Project is responsible for establishing intestinal dysbiosis as a mediator of inflammatory bowel disease, obesity, and neurodevelopmental disorders in adults. Recent advances in metagenomics implicate gut microbiota and diet as key modulators of the bidirectional signaling pathways between the gut and brain that underlie neurodevelopmental and psychiatric disorders in adults. Evidence linking intestinal dysbiosis to neurodevelopmental disease outcomes in preterm infants is emerging. Recent clinical studies show that intestinal dysbiosis precedes late-onset neonatal sepsis and necrotizing enterocolitis in intensive care nurseries. Moreover, strong epidemiologic evidence links late-onset neonatal sepsis and necrotizing enterocolitis in long-term psychomotor disabilities of very-low-birth-weight infants. The notion of the gut-brain axis thereby supports that intestinal microbiota can indirectly harm the brain of preterm infants. In this review, we highlight the anatomy and physiology of the gutbrain axis and describe transmission of stress signals caused by immune-microbial dysfunction in the gut. These messengers initiate neurologic disease in preterm infants. Understanding neural and humoral signaling through the gut-brain axis will offer insight into therapeutic and dietary approaches that may improve the outcomes of very-low-birth-weight infants.

$\mathbf{T}$ he concept of gut-brain axis (GBA) has existed for more than three decades (1). Contributions from many scientific disciplines have now resulted in the acceptance of a multicomponent bidirectional signaling system between the gut and the brain (2). The initiation of the Human Microbiome project (3) has been associated with recent and rapid advances in GBA-related research $(4,5)$. We propose that the GBA plays a vital role in adverse neurodevelopmental outcomes in preterm infants. This review focuses on the impact of GBA in the health and disease of preterm infants, although clinical research on the GBA is sparse in this population. Hence, we include GBA-related investigations in neonatal animals using relevant experimental models that allowed us to highlight gaps in knowledge that require additional investigation.

\section{THE GBA}

Gastrointestinal motor and sensory components send messages to the central nervous system and the return response to the intestine is the definition of the brain-gut axis (6). Figure 1 shows the complexity and the modifiers of GBA-related signaling pathways and the multiorgan connections that influence the balance of health vs. disease in the preterm newborn. The brain is the central component of the GBA and includes connections between the cerebral cortex, the limbic system, the hypothalamic-pituitary axis, and the brain stem. The limbic cortex regulates olfaction and integrates sensory and motor functions. The limbic system receives input from other brain regions responsible for a range of behaviors. Maternal deprivation and pain studies in neonatal mice $(7,8)$ indicate that the limbic system plays an important role in development of the hippocampus. In preterm infants without intracranial hemorrhage or ischemia, injury to the hippocampus is likely responsible for neurobehavioral disorders seen in preterm infants during childhood (9). When studying insults to the limbic system, researchers must consider gender-specific effects of stress in human preterm infants (10).

The peripheral components of the GBA communicate with the central nervous system through the enteric, autonomic, and sympathetic nervous systems $(11,12)$. Evidence that gut microbes modulate neural signaling indicates that they may alter brain development and function (12) via the enteric nervous system (ENS). The ENS resides within intestinal wall and abnormalities in the ENS are associated with a wide spectrum of gastrointestinal disorders in adults (13). The GBA and neonatal diseases section discusses newborn diseases associated with the ENS. The ENS communicates with the brain via the vagus nerve and dorsal root and nodose ganglia (11). The hypothalamic-pituitary axis, the autonomic nervous system, and the sympathetic nervous system are integrated peripheral components of the GBA (14). The afferent vagus nerve is a major retrograde signaling system from gut to brain (15). The efferent vagus nerve-based cholinergic anti-inflammatory pathway is known to regulate the balance of tumor necrosis factor-alpha, high mobility group box 1 (a nonhistone nuclear protein), and other cytokines secreted by macrophages in response to stress signals in the gut (16). This inflammation can result in the

\footnotetext{
'Department of Child Health, School of Medicine, University of Missouri, Columbia, Missouri; ${ }^{2}$ Department of Molecular Microbiology and Immunology, School of Medicine, University of Missouri, Columbia, Missouri; ${ }^{3}$ Department of Neurology, School of Medicine, University of Missouri, Columbia, Missouri; ${ }^{4}$ Newborn Medicine, Nemours Children's Hospital, Orlando, Florida. Correspondence: Michael P. Sherman (shermanmp@missouri.edu)
} 


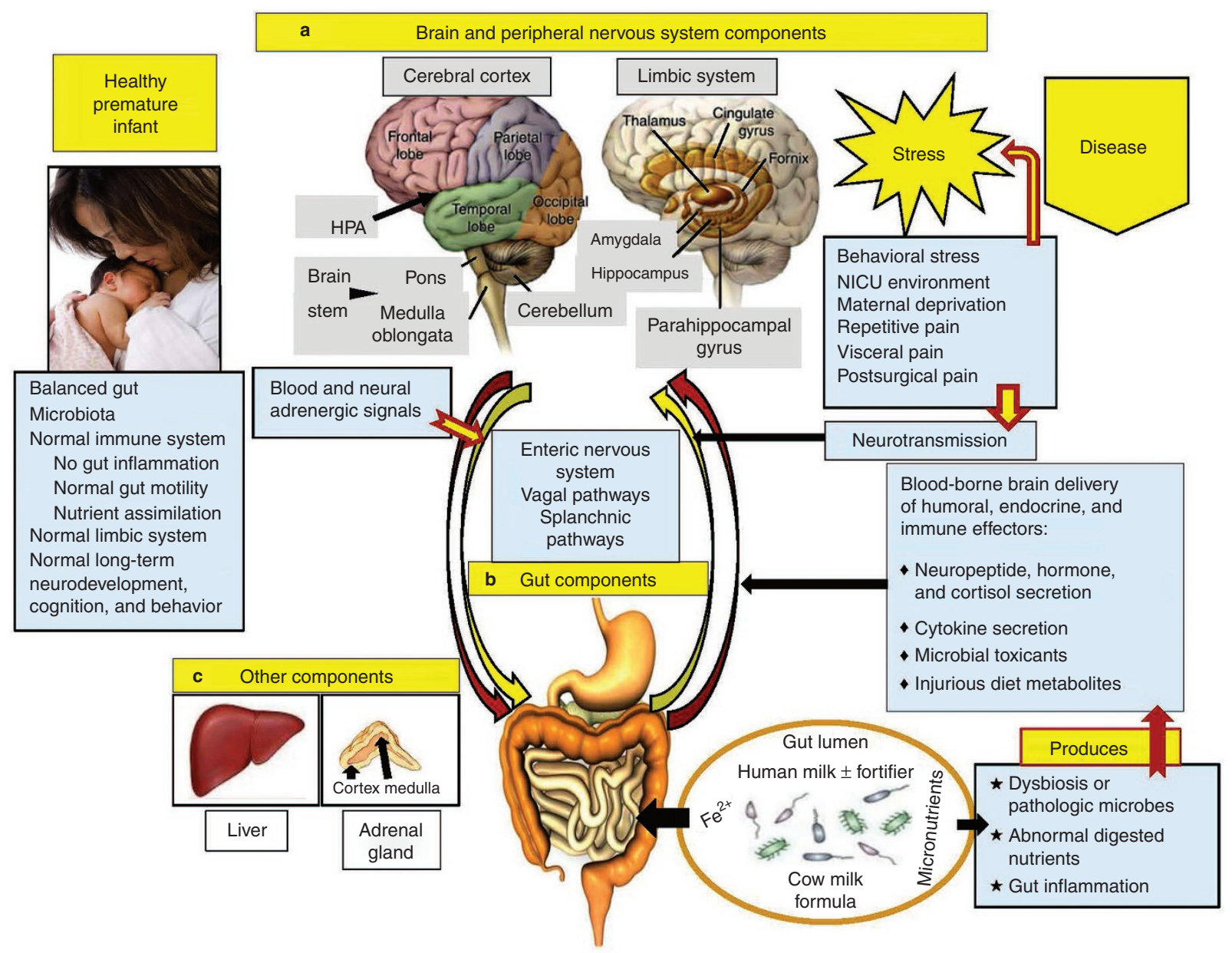

Figure 1. The gut-brain axis (GBA). The central part of the figure shows the brain, the peripheral nervous systems, and the gut components of the GBA. HPA indicates the hypothalamic-pituitary axis. The gut component includes microbiota and nutrients in the intestinal lumen. The adrenal gland and the liver are also organs associated with GBA signaling. The left side of this figure shows a healthy preterm infant and a normally functioning GBA. The right side of the figure shows stress, endocrine, and immune signals transmitted to the brain via the peripheral nervous systems or blood-borne biomolecules. Intestinal microbiota, enteral nutrients, and environmental stress produce signals that can cause central nervous system, liver, or bowel diseases.

loss of intestinal epithelial barrier function allowing bacterial invasion (17). A concurrent increase in intestinal permeability leads to activation of immune and somatic cells through pathogen-associated molecular pattern recognition receptors that trigger inflammation in the gut (17). Signals sent through the systemic and intestinal immune system via the GBA cause alterations in brain function and disease (18).

The ENS, autonomic nervous system, and the hypothalamicpituitary axis transduce neural and humoral signals about nutrients and microbes in the gut to the brain and the limbic system (18). The hypothalamus possesses reciprocal connections between the higher cortical centers such as the reward-related limbic system and the brain stem (19). During a stressful state, hormone and neuropeptide secretion in the gut ultimately invokes cortisol release from the adrenal gland via signals through the hypothalamus. Gut hormones, namely peptide YY, pancreatic polypeptide, glucagon-like peptide-1, oxyntomodulin, are components of the GBA associated with eating and satiety, while fasting increases ghrelin secretion $(19,20)$. The GBA also influences intestinal immune cells with neuropeptide messages. Specific neuropeptides, namely vasoactive intestinal peptide and norepinephrine, modulate functions of dendritic cells and T cells located throughout the wall of the intestine and in secondary lymphoid tissues like Peyer's patches (21). Depending on the balance of neuropeptides and other immunomodulatory molecules, dendritic cells orchestrate the differentiation of distinct effector lymphocytes populations by either triggering inflammatory or anti-inflammatory (tolerogenic) responses to microbial and/or dietary antigens. Finally, adrenergic stimulation of intestinal enterocytes through the sympathetic nervous system can alter gut microbial composition and the change can result in a loss of barrier function and increased gut permeability (12).

\section{DISEASES RELATED TO DISORDERS OF THE GBA IN THE FETUS AND NEONATE}

During pre- and postnatal life, coordinated neural, intestinal motor and absorptive functions, and immunologic functions ensure a healthy newborn infant and promote continued growth and development through infancy and childhood. A normal vs. an abnormal GBA involves multiple interactive cells and organs that create either health or disease (Figure 1). Pediatricians are familiar with morphologic defects in the 
ENS. Congenital defects in the ENS causes Hirschsprung's disease that heightens the risk of enterocolitis (22). Intestinal neuronal dysplasia is a particularly lethal developmental disease of the ENS that causes megalocystis, megacolon, and malrotation (23). Gut motor dysfunction is associated with myelomeningocele and acquired adult diseases such as acute spinal cord injury. Congenital or acquired spinal cord diseases alter ENS activity and cause a nonanatomic, neurogenic intestinal obstruction syndrome (24).

Congenital defects are not the only events that can occur in the fetus and affect development of the ENS. The use of selective serotonin re-uptake inhibitors (SSRIs) during human pregnancy has raised concerns about abnormal development of the ENS (25). Investigations of newborns exposed in utero to SSRIs have observed eating disorders, altered motor activity, and behavioral abnormalities (26); findings that appear related to abnormalities in the autonomic nervous system. The exposure of the fetus to SSRIs during pregnancy is manifest by (i) delayed developmental milestones in infantile speech (26) and (ii) behavioral problems after infancy (27). We need to know more about how SSRIs (28), as well as medications like valproic acid (29), that are administered during pregnancy produce "defects" in the human fetal ENS. The use of SSRIs during pregnancy may also be involved in the pathogenesis of autism spectrum disorders (ASD) (30), although the mechanisms by which SSRIs influence nervous system development are incompletely studied. Rats given the antipsychotic drug, olanzapine, which balances dopamine and serotonin in the brain produced increased plasma levels of proinflammatory cytokines, caused macrophage infiltration of adipose tissue, and modified the composition of the fecal microbiota (31). This study provides a rationale how fetal exposure to SSRIs may cause ASD.

\section{GBA INTERACTIONS WITH GUT MICROBIOTA, EPITHELIA, AND IMMUNE CELLS}

This subject considers the interactions between the gut microbiota, intestinal epithelia, and the immune system related to physiology in the GBA (Figure 2). Since they are in close

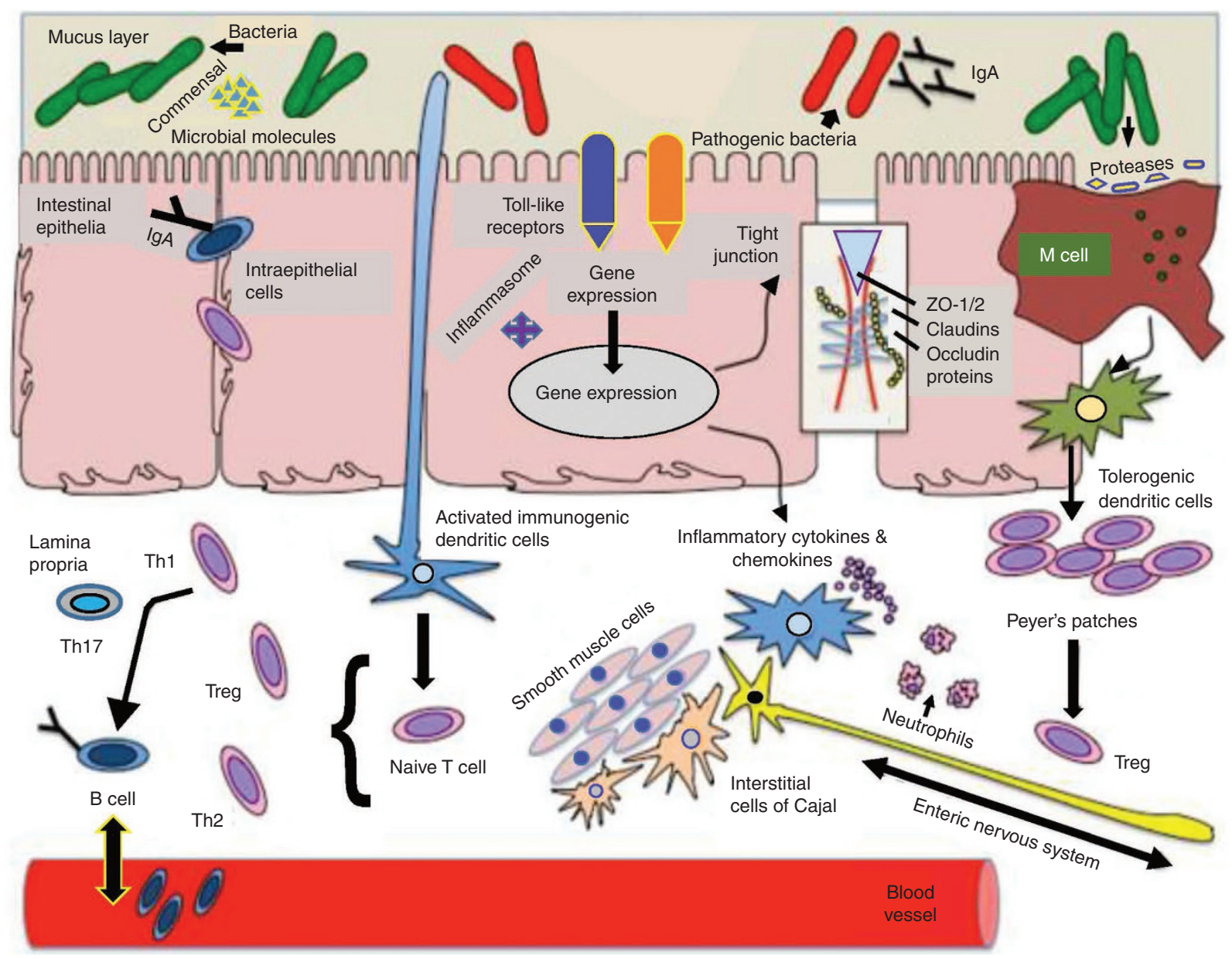

Figure 2. Intestinal components of the gut-brain axis (GBA). The illustration displays the interactions of commensal and pathogenic bacteria with receptors on or in enterocytes, dendritic cells, and $\mathrm{M}$ cells. Gut microbiota and dietary components can alter the functions of gap junction proteins and increase intestinal permeability. Signals arising from receptors that identify danger or stress trigger immune cells and lymphoid aggregates in the lamina propria. Gap junctions send signals to the interstitial cells of Cajal and other elements of the enteric nervous system (ENS). In neonates, a critical event is maturation of dendritic cells that secrete interleukin-12 and promote the emergence of Th1 cells and reversing fetal Th1:Th2 bias (69). Th17 cells also emerge and participate in mucosal host defense. (Reprinted from Figure 1 in: Di Mauro A, Neu J, Riezzo G, et al. Gastrointestinal function development and microbiota. Ital J Pediatr 2013;39:15; Licensee BioMed Central Ltd.) 


\section{Review $\mid$ Sherman e tal.}

proximity, gut microbiota can stimulate and regulate gut epithelia, intestinal immune cells and tissues, and the ENS (3234). Publications involving preterm infants are limited on this topic; however, a review describes the important role played by intestinal microbiota in the postnatal development of gastrointestinal functions (35). Recent studies suggest that postnatal events, such as antibiotic administration, modify neonatal gut microbiota and are associated with obesity in infancy and childhood (36). Strict antibiotic stewardship is mandatory in neonatal intensive care units until the links between postnatal antibiotics and future obesity have been verified (37). The basis for an association between gut microbiota and obesity is increased energy harvest (38). Studies in obese vs. lean twins show phylum-level alterations in the gut microbiota, including reduced bacterial diversity, an altered representation of bacterial genes in the microbiome and abnormal metabolic pathways suggesting that these differences account for the lean vs. the obese state (39). Obese individuals have fecal microbial biomarkers related to their diet, and these microbiota correlate with impaired metabolic health (40). Intestinal microbes can create an environment that promotes energy salvage from the diet. For example, Faecalibacterium prausnitzii is a bacterium that promotes epithelial health and is a prominent intestinal inhabitant of south Indian children with obesity (41). The effects of the gut microbes extend beyond the pathophysiology of obesity and influence the incidence of type 2 diabetes (42) and demyelinating illnesses, psychiatric disease, behavioral disorders, and irritable bowel syndrome (43).

Figure 2 depicts the recognition of commensal and pathogenic microbiota and the communication-related pathways between intestinal epithelia, dendritic cells, and other underlying immune cells. The development of tolerance shows $M$ cells overlying Peyer's patches and dendritic cells engaging antigens for processing and presentation. The recognition of antigens associated with pathogenic bacteria in the intestinal lumen stimulates production of secretory IgA. Binding of secretory $\operatorname{IgA}$ to invasive microbes in intestinal fluid and in the mucin layer blocks invasion of intestinal epithelia (17). Antimicrobial peptides secreted by enterocytes into the mucin layer also hinder microbial invasion of the gut barrier (17). Lipopolysaccharide from the cell wall of Enterobacteriaceae living in the gut binds to Toll-like receptor- 4 on enterocytes. This pathogen-associated molecular pattern recognition causes neural transmissions via the vagus, while intestinal immune cells are stimulated to produce cytokines $(17,44)$. Mice that have ileitis caused by Toxoplasma gondii infection have activated Toll-like receptor-9 in their enterocytes. In the absence of cerebral infection caused by T. gondii, the brain tissue of these mice had elevated levels of proinflammatory cytokines (45). This study persuasively reveals pathogen-specific infection and inflammation in the gut can cause immune-mediated inflammation in the brain.

Additional data suggest innate immune cells in the gut recognize microbial and other damage-related signals with help from the inflammasome. The inflammasome is a multiprotein cytoplasmic complex that activates one or more caspases that process and enhance secretion of proinflammatory cytokines in response to microbial pathogens and other stress response proteins. Characteristically, innate immune cells release interleukin-1, interleukin-18, and interleukin-33 (46); however, inhibitory signals from the inflammasome may also downregulate inflammation in the gut (47). For example, in a mouse model of murine enteritis, efferent vagal signaling via corticotropin-releasing hormone inhibits inflammasome-induced inflammation, thereby reducing intestinal enteritis $(16,48)$. The GBA thereby can regulate inflammasome-mediated activation of innate immune cells in the gut through the action of the hypothalamic-pituitary axis, thereby abrogating inflammation in the intestine.

Other model systems indicate that gut microbiota transduce either inflammatory or protective (anti-inflammatory) signals in the GBA (49). Escherichia coli interactions with gut epithelia transmit inflammatory responses, whereas $F$. prausnitzii stimulate anti-inflammatory responses akin to other commensal bacteria like Lactobacillus casei and Bacteroides thetaiotaomicron. Commensal flora may promote protective responses by increasing mucin production by intestinal epithelia $(50,51)$, a critical host defense against microbial invasion (17). Moreover, B. thetaiotaomicron heightens expression of angiogenin 4 in crypt Paneth cells (52); angiogenin4 is a dual function protein that acts as an antimicrobial peptide (52) and as an angiogenic factor promoting growth and health in intestinal villi (53). Thus, commensal bacteria provide homeostasis and health in the developing gut.

Necrotizing enterocolitis (NEC) is a disease characterized by intestinal dysbiosis and intestinal inflammation affecting mostly preterm newborns (17). When NEC complicates the hospital stay, there is a higher risk for substantial long-term neurodevelopmental abnormalities (54). The stress created by NEC has adverse consequences in the brain via the GBA (55). Microbial toxicants and proinflammatory cytokines released into the systemic circulation from infected and damaged intestine have a causal relationship with the long-term psychomotor and intestinal disabilities seen after NEC (55). The degree of injury to the intestine in NEC correlates with the levels of oxidant stress and other mediators associated with brain injury (56). The role of the GBA in the pathogenesis of cerebral palsy and ASD requires more research in immature infants.

Infectious and noninfectious diseases, however, may activate intestinal inflammation in utero (57). Of course, fetal gut infection and inflammation assumes the fetus swallows bacterial pathogens into the stomach before birth. Fetal swallowing does not occur before $29-31$ wk of gestation. During antenatal infections, experts have proposed the cholinergic, antiinflammatory system sends signals to intestinal macrophages to inhibit cytokine secretion (58). This notion is conceptually correct because Ureaplasma parvum and Ureaplasma urealyticum are the most common organisms isolated from infected amniotic fluid, and are associated with preterm labor (59). Respiratory colonization with Ureaplasma doubles the risk of developing NEC in very preterm infants (60). The association of Ureaplasma with NEC still requires the molecular presence 
of this microbe in either surgical specimens or feces of infants who develop NEC.

After birth, however, alterations in the intestinal microbiota and the development of "dysbiosis" is probably the key event associated with the pathogenesis of NEC (61). Fecal samples have identified a bloom or sharp increase in the phylum Proteobacteria between $7 \mathrm{~d}$ and $<72 \mathrm{hr}$ before the onset of NEC cases (62). The study found unclassified members of the family Enterobacteriaceae as potential pathogens, but no particular genus and species were consistently associated with infants that developed NEC. Dysbiosis of the intestinal microbiota is also a risk factor for late-onset neonatal sepsis in very preterm infants $(63,64)$. These insights about the gut microbiome and the pathogenesis of late-onset neonatal sepsis or NEC in very preterm infants have come forth because of metagenomics. Metagenomics is the study of microbes, their genes, and their metabolites from a defined environment, like the intestines. Metagenomic methods utilize analytical instruments that can define the molecular signatures of microbes in specific habitats. Analyses of those signatures involve software applications that characterize the microbial ecology in environmental samples. The analytical instruments, the molecular methods, the bioinformatics, and the representations of the data associated with metagenomic studies are often unfamiliar to caregivers in the neonatal intensive care units. A recent review of metagenomics describes the culture-independent methods used to identify microbes in human neonatal organs (65). The interstitial cells of Cajal are the pacemaker of the intestine and activate the muscularis mucosae in a rhythmic fashion (66). Gut motility can help remove pathogenic bacteria from the bowel lumen by defecation. Bacterial toxins in the intestinal fluid, such as a high endotoxin content, reduce ENS activity and are likely responsible for ileus before the onset of NEC (67). Ileus in very preterm infants should alert caregivers to the scenario that toxins in the intestine are inhibiting interstitial cells of Cajal activity. Most neonatologists know that ileus points to NEC on the horizon, but the preceding rationale defines the physiology. The gut microbiota are essential for the development and function of the gastrointestinal and the systemic immune system $(12,34,43)$. A Th2:Th1 lymphocyte bias is associated with pregnancy maintenance and fetal well-being (68). The Th2 bias seen in neonates is probably a spillover of immunosuppression during human pregnancy. Studies in neonatal mice suggest the immunologic milieu renders neonates susceptible to infection. Postnatal immune events in the intestine are associated with microbial colonization that reverses neonatal Th2:Th1 bias and lowers the risk of postnatal infection (69).

Table 1 summarizes stressors before and after birth that may cause brain injury in conjunction with the GBA concept. The list of stressors is not exhaustive, since this paper describes a number of adverse neurologic consequences of common intestinal diseases throughout the review. Examples shown in Table 1 are illustrative of the unusual conditions seen with diseases involving the GBA. We selected stress states in the gut

Table 1. Fetal and neonatal stress states responsible for brain injury: role of gut-brain axis

\begin{tabular}{|c|c|c|c|}
\hline Condition & Pathophysiology & Effectors of injury & References \\
\hline \multicolumn{4}{|c|}{ Intestinal or other conditions causing stress and brain injury in the fetus before birth } \\
\hline AF infection & $\begin{array}{l}\text { Swallowed infected or proinflammatory AF } \\
\text { biomolecules }\end{array}$ & $\begin{array}{l}\text { AF, gut or fetal blood cytokines, oxidants, and } \\
\text { microbial toxins }\end{array}$ & 70,71 \\
\hline $\begin{array}{l}\text { Prolonged rupture of membranes/ } \\
\text { chorioamnionitis }\end{array}$ & $\begin{array}{l}\text { Swallowed infected or proinflammatory agents } \\
\text { in AF }\end{array}$ & Maternal fever, fetal inflammatory response & 72,73 \\
\hline Fetal cocaine exposure & Gut and brain ischemia, necrotizing enterocolitis & Oxidant stress, necrosis, inflammation & 74 \\
\hline \multicolumn{4}{|c|}{ Intestinal or other conditions causing stress and brain injury in VLBW infants after birth } \\
\hline $\begin{array}{l}\text { Volvulus and intussusception } \\
\text { occurring in antenatal or postnatal } \\
\text { period }\end{array}$ & Malrotation, other pathology, gut ischemia & Oxidant stress, "cytokine storm" from necrosis & 77 \\
\hline $\begin{array}{l}\text { Relative adrenal insufficiency in the } \\
\text { preterm, congenital enzyme defects } \\
\text { (cortisol production), adrenal gland } \\
\text { hemorrhage, death }\end{array}$ & $\begin{array}{l}\text { Hemodynamic instability, poor cardiac } \\
\text { performance and reduced vascular tone }\end{array}$ & $\begin{array}{l}\text { Low blood cortisol levels during stress, } \\
\text { excess nitric oxide production, unstable cell } \\
\text { membranes }\end{array}$ & 82 \\
\hline $\begin{array}{l}\text { Pre- and/or postnatal hypoxic- } \\
\text { ischemic encephalopathy }\end{array}$ & $\begin{array}{l}\text { Reoxygenation and reperfusion insults; failed } \\
\text { cortisol response; concurrent brain trauma, } \\
\text { dysphagia, poor tone in lower esophageal } \\
\text { sphincter, small and large bowel dysmotility }\end{array}$ & $\begin{array}{l}\text { Severe acute or recurrent hypoxia } \pm \text { ischemia, } \\
\text { metabolic acidosis, reactive } \mathrm{O}_{2} \text { and } \mathrm{N}_{2} \text { species, } \\
\text { abnormal mitochondrial metabolism, } \\
\text { cytokine-driven inflammation }\end{array}$ & 83,84 \\
\hline
\end{tabular}

AF, amniotic fluid; ENS, enteric nervous system; NEC, necrotizing enterocolitis; SIP, spontaneous intestinal perforation; VLBW, very low birth weight. 


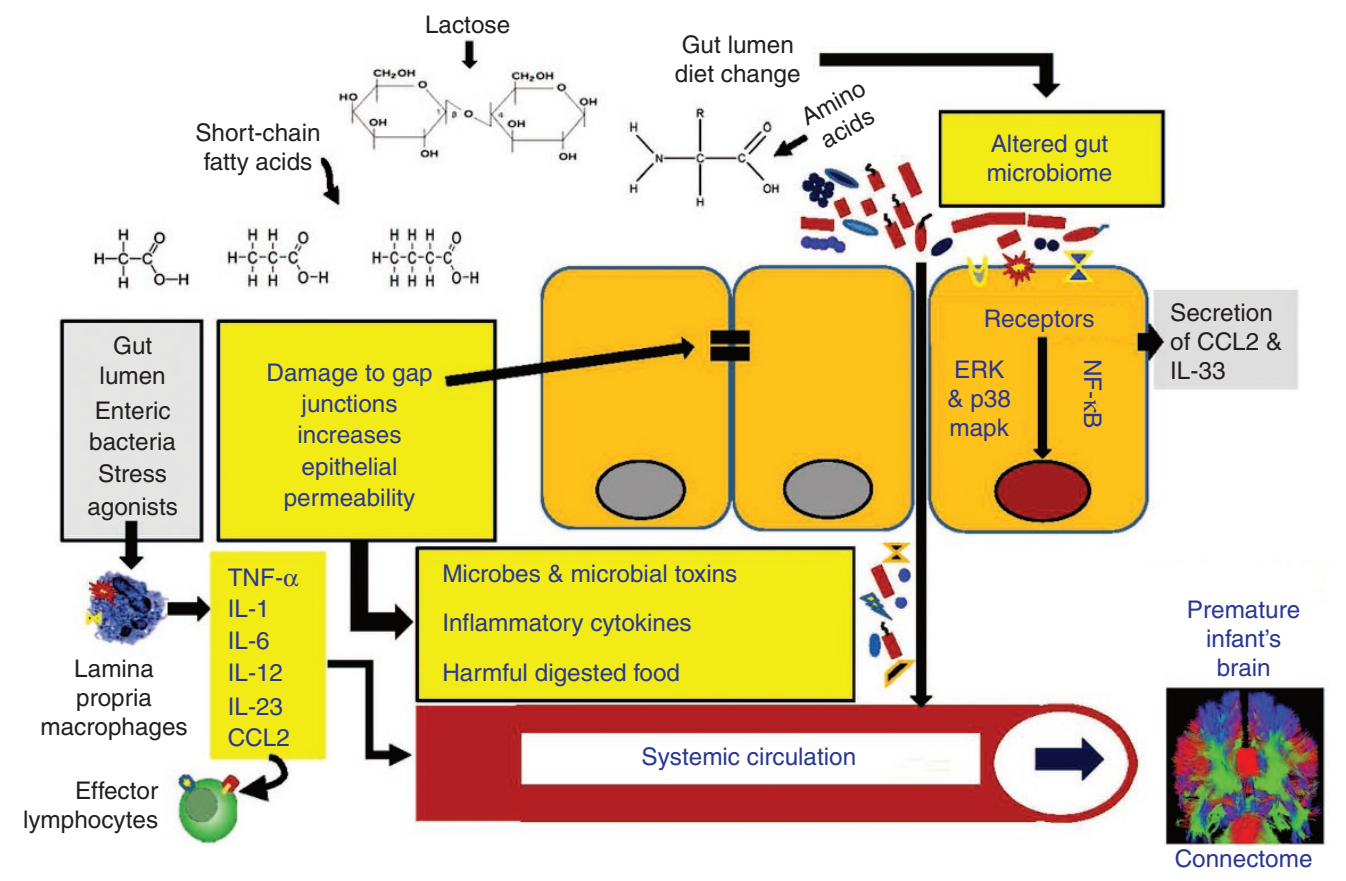

Figure 3. Loss of gut barrier protection and increased permeability. A dietary change initiates an increase in microbial toxins, harmful digested food metabolites, and/or increased microbial invasiveness. Injury to gap junctions or enterocytes is the key to the pathophysiology that stimulates an inflammatory response. The red nucleus in the far right enterocyte signifies these cells can die by apoptosis or necrosis. The far right enterocyte also displays transcription factors that induce either a death paradigm or inflammation. In turn, gut-related biomolecules enter the systemic circulation, reaching and damaging the white matter tracts or connectome in the brain of preterm infants.

before and after birth, which were relevant to pathophysiology associated with the GBA (70-84).

\section{NEONATAL NUTRITION AND MODIFICATIONS OF GBA FUNCTION}

While microbial colonization of the gut is important for immune system development, it also acts in concert with diet to promote healthy brain development $(85,86)$. Human milk contains many biofactors that improve health and brain development (87). To assure its availability, neonatal intensive care unit caregivers often freeze a mother's milk before use; however, freezing reduces the immunologic protective components in human milk. Compared with pasteurization of human milk, freezing maintains more immune properties in human milk than does heat treatment $(88,89)$. In other words, fresh colostrum and milk contains lactoferrin, lysozyme, other antimicrobial proteins and immunomodulatory agents that prevent NEC $(89,90)$. A human milk oligosaccharide, disialyllacto-Ntetraose, prevents NEC in a neonatal rat model (91). Several mechanisms define the beneficial effects of human milk oligosaccharides in the immature intestinal tract of human preterm infants. NEC is an intestinal disease of preterm infants, which produces intense inflammation (92) and indirect brain injury via the GBA $(55,72)$. The preceding reasons are why we emphasize feeding colostrum right after birth and give freshly expressed mother's milk during the neonatal intensive care unit stay $(90,93,94)$. The use of fresh maternal milk will result in colonization of the gut with healthy commensal bacteria, particularly probiotic bacteria that utilize human milk oligosaccharides for their nutrition $(90,93)$. For this reason, fresh human milk enables development of a healthy ENS and GBA (5). In the absence of a mother's own milk, neonatal caregivers propose using donor human milk as the nutrient of choice instead of infant formula. When human donor milk undergoes holder pasteurization before use, the thermal processing significantly reduces the immunomodulatory and antimicrobial properties of proteins in the milk (89). Hence, pasteurization and freeze thawing make donor human milk a suboptimal antimicrobial and immunomodulatory nutrient. When human donor milk is compared with a mother's own milk, the composition of human milk oligosaccharides was significantly different (94) suggesting that the antimicrobial benefits of donor milk and its ability to promote the assembly of a commensal microbial flora need more scrutiny if a healthy GBA is to be established.

The preceding reports led us to examine how the diet of verylow-birth-weight preterm infants played a role in the GBA. Fresh and unadulterated mother's milk is the ideal nutrient to prevent NEC and to support optimal development and outcomes. Friel (95) found high levels of urinary F2-isoprostane, a biomarker of oxidant stress, when preterm infants received mother's milk with $>50 \%$ fortification. This investigation did not examine urinary isoprostanes when preterm infants received regular or high-density caloric formulas. However, a recent study found digested formula, but not digested fresh human milk caused death of neutrophils, endothelia, and intestinal epithelia in vitro (96). The researchers implied that these findings have relevance to the pathogenesis of NEC. The stress 


\section{Microbes and neonatal gut-brain axis}

response seen after feeding fortified human milk and preterm cow milk-based formula is likely detrimental to brain development by way of harmful signaling through the GBA $(43,97,98)$. Figure 3 describes the dietary, microbial, and immune events associated with brain injury in preterm infants. We emphasize that these factors may also influence intestinal barrier function and promote invasion and translocation of pathogenic microbes that cause late-onset neonatal sepsis and NEC (17).

Feeding probiotics to very preterm infants has reduced the occurrence of NEC (99). Recent studies show probiotic bacteria release inhibitors of tumor necrosis factor-alpha and its downstream target nuclear factor-kappa B (100). A recent review also says probiotic bacteria release inhibitors of tumor necrosis factor-alpha and its downstream target nuclear factor-kappa B (101). Researchers also propose that probiotics prevent brain injury by blocking the transport of damaging biomolecules via the GBA $(43,86)$.

If one excludes intracranial hemorrhage and ischemia as principal contributors to brain injury in preterm infants, these infants still have three times the risk of developing ASD (102). A recent and compelling report showed that oral treatment of offspring with Bacteroides fragilis prevented autistic behavior in an animal model of ASD (103). The researchers proposed that $B$. fragilis reduced intestinal permeability and improved behavioral symptoms suggesting an altered gut microbiome plays a role in the pathogenesis of ASD. The mechanism of prevention may be an enteric anti-inflammatory milieu (interleukin-10 production) in neonatal mice after they received enteral B. fragilis_(104).

Central nervous system injury in preterm infants often localizes to the white matter tracts (i.e., connectome) in the brain (105). Hence, imaging techniques that define injury to the connectome is receiving high interest $(106,107)$. Injurious agents or neurotransmissions from the gut that reach the brain of preterm infants via the GBA are probably causes of brain injury $(45,55)$. Advanced imaging techniques have used functional magnetic resonance imaging, magnetoencephalography, and positron emission tomography for interrogating neuronal pathways. If metagenomic techniques applied to the gut microbiota in conjunction with brain imaging, researchers will surely identify instigators of injury associated with the GBA, and the findings will correlate with human health and disease (106-108).

\section{CONCLUSIONS AND FUTURE RESEARCH CONSIDERATIONS}

Pediatric investigators must focus on the GBA of the fetus or preterm neonate, because adverse effects in their environment may be the origins of neurodevelopmental disease seen during childhood or adult life. In this review, examples of the developmental origins of disease that involve GBA have included autism and obesity. In the future, research must be devoted to neurologic disease arising from abnormalities in the GBA and obtain concrete proof of mechanisms operative in early life. The Human Microbiome Project collected and analyzed feces from preterm and term infants. The molecular findings related to gut microbes in those analyses need correlation with the development of cerebral palsy, autism, or other neurologic abnormalities that occur in very-low-birth-weight infants (109).

\section{STATEMENT OF FINANCIAL SUPPORT}

A University of Missouri Research Board grant and the Leda Sears Trust support M.P.S. The J. Lavenia Edwards endowment and Leda Sears Trust funds support H.Z. The Sears Trust and J. Lavenia Edwards endowment are funds provided by the Department of Child Health, University of MissouriColumbia.

Disclosure: The authors have no financial disclosures or conflicts of interest.

\section{REFERENCES}

1. Track NS. The gastrointestinal endocrine system. Can Med Assoc J 1980;122:287-92.

2. Stilling RM, Dinan TG, Cryan JF. Microbial genes, brain \& behaviour-epigenetic regulation of the gut-brain axis. Genes Brain Behav 2014;13:69-86.

3. NIH HMP Working Group. Peterson J, Garges S, Giovanni M, et al. The NIH Human Microbiome Project. Genome Res 2009;19:2317-23.

4. Bercik P, Collins SM, Verdu EF. Microbes and the gut-brain axis. Neurogastroenterol Motil 2012;24:405-13.

5. Saulnier DM, Ringel Y, Heyman MB, et al. The intestinal microbiome, probiotics and prebiotics in neurogastroenterology. Gut Microbes 2013;4:17-27.

6. Jones MP, Dilley JB, Drossman D, Crowell MD. Brain-gut connections in functional GI disorders: anatomic and physiologic relationships. Neurogastroenterol Motil 2006;18:91-103.

7. O'Sullivan E, Barrett E, Grenham S, et al. BDNF expression in the hippocampus of maternally separated rats: does Bifidobacterium breve 6330 alter BDNF levels? Benef Microbes 2011;2:199-207.

8. Juul SE, Beyer RP, Bammler TK, Farin FM, Gleason CA. Effects of neonatal stress and morphine on murine hippocampal gene expression. Pediatr Res 2011;69:285-92.

9. Perlman JM. Cognitive and behavioral deficits in premature graduates of intensive care. Clin Perinatol 2002;29:779-97.

10. Pimentel-Coelho PM, Michaud JP, Rivest S. Evidence for a gender-specific protective role of innate immune receptors in a model of perinatal brain injury. J Neurosci 2013;33:11556-72.

11. Udit S, Gautron L. Molecular anatomy of the gut-brain axis revealed with transgenic technologies: implications in metabolic research. Front Neurosci 2013;7:134.

12. Forsythe P, Kunze WA. Voices from within: gut microbes and the CNS. Cell Mol Life Sci 2013;70:55-69.

13. Knowles CH, Lindberg G, Panza E, De Giorgio R. New perspectives in the diagnosis and management of enteric neuropathies. Nat Rev Gastroenterol Hepatol 2013;10:206-18.

14. Bonaz BL, Bernstein CN. Brain-gut interactions in inflammatory bowel disease. Gastroenterology 2013;144:36-49.

15. Matteoli G, Boeckxstaens GE. The vagal innervation of the gut and immune homeostasis. Gut 2013;62:1214-22.

16. Parrish WR, Rosas-Ballina M, Gallowitsch-Puerta M, et al. Modulation of TNF release by choline requires alpha7 subunit nicotinic acetylcholine receptor-mediated signaling. Mol Med 2008;14:567-74.

17. Sherman MP. New concepts of microbial translocation in the neonatal intestine: mechanisms and prevention. Clin Perinatol 2010;37:565-79.

18. Mayer EA. Gut feelings: the emerging biology of gut-brain communication. Nat Rev Neurosci 2011;12:453-66.

19. Pimentel GD, Micheletti TO, Pace F, Rosa JC, Santos RV, Lira FS. Gut-central nervous system axis is a target for nutritional therapies. Nutr J 2012;11:22.

20. Côté CD, Zadeh-Tahmasebi M, Rasmussen BA, Duca FA, Lam TK. Hormonal signaling in the gut. J Biol Chem 2014;289:11642-9.

21. Maldonado RA, von Andrian UH. How tolerogenic dendritic cells induce regulatory T cells. Adv Immunol 2010;108:111-65.

22. Gershon MD, Ratcliffe EM. Developmental biology of the enteric nervous system: pathogenesis of Hirschsprung's disease and other congenital dysmotilities. Semin Pediatr Surg 2004;13:224-35.

23. Pini Prato A, Rossi V, Fiore M, et al. Megacystis, megacolon, and malrotation: a new syndromic association? Am J Med Genet A 2011;155A: 1798-802. 
24. Awad RA. Neurogenic bowel dysfunction in patients with spinal cord injury, myelomeningocele, multiple sclerosis and Parkinson's disease. World J Gastroenterol 2011;17:5035-48.

25. Nijenhuis CM, ter Horst PG, van Rein N, Wilffert B, de Jongvan den Berg LT. Disturbed development of the enteric nervous system after in utero exposure of selective serotonin re-uptake inhibitors and tricyclic antidepressants. Part 2: testing the hypotheses. Br J Clin Pharmacol 2012;73:126-34.

26. Weikum WM, Oberlander TF, Hensch TK, Werker JF. Prenatal exposure to antidepressants and depressed maternal mood alter trajectory of infant speech perception. Proc Natl Acad Sci USA 2012;109:Suppl 2:17221-7.

27. Smith MV, Sung A, Shah B, Mayes L, Klein DS, Yonkers KA. Neurobehavioral assessment of infants born at term and in utero exposure to serotonin reuptake inhibitors. Early Hum Dev 2013;89:81-6.

28. Hanley GE, Oberlander TF. Neurodevelopmental outcomes following prenatal exposure to serotonin reuptake inhibitor antidepressants: a "social teratogen" or moderator of developmental risk? Birth Defects Res A Clin Mol Teratol 2012;94:651-9.

29. Christensen J, Grønborg TK, Sørensen MJ, et al. Prenatal valproate exposure is associated with autism spectrum disorder and childhood autism. JAMA 2013;309:1696-703.

30. Unwin LM, Maybery MT, Wray JA, Whitehouse AJ. A "bottom-up" approach to aetiological research in autism spectrum disorders. Front Hum Neurosci 2013;7:606.

31. Davey KJ, O’Mahony SM, Schellekens H, et al. Gender-dependent consequencesofchronicolanzapineintherat:effectsonbodyweight,inflammatory, metabolic and microbiota parameters. Psychopharmacology (Berl) 2012; 221:155-69.

32. Round JL, Mazmanian SK. The gut microbiota shapes intestinal immune responses during health and disease. Nat Rev Immunol 2009;9:313-23.

33. Sekirov I, Russell SL, Antunes LC, Finlay BB. Gut microbiota in health and disease. Physiol Rev 2010;90:859-904.

34. Putignani L, Del Chierico F, Petrucca A, Vernocchi P, Dallapiccola B. The human gut microbiota: a dynamic interplay with the host from birth to senescence settled during childhood. Pediatr Res 2014;76:2-10.

35. Di Mauro A, Neu J, Riezzo G, et al. Gastrointestinal function development and microbiota. Ital J Pediatr 2013;39:15.

36. Trasande L, Blustein J, Liu M, Corwin E, Cox LM, Blaser MJ. Infant antibiotic exposures and early-life body mass. Int J Obes (Lond) 2013;37:16-23.

37. Tripathi N, Cotten CM, Smith PB. Antibiotic use and misuse in the neonatal intensive care unit. Clin Perinatol 2012;39:61-8.

38. Turnbaugh PJ, Ley RE, Mahowald MA, Magrini V, Mardis ER, Gordon JI. An obesity-associated gut microbiome with increased capacity for energy harvest. Nature 2006;444:1027-31.

39. Turnbaugh PJ, Hamady M, Yatsunenko T, et al. A core gut microbiome in obese and lean twins. Nature 2009;457:480-4.

40. Korpela K, Flint HJ, Johnstone AM, et al. Gut microbiota signatures predict host and microbiota responses to dietary interventions in obese individuals. PLoS One 2014;9:e90702.

41. Balamurugan R, George G, Kabeerdoss J, Hepsiba J, Chandragunasekaran AM, Ramakrishna BS. Quantitative differences in intestinal Faecalibacterium prausnitzii in obese Indian children. Br J Nutr 2010;103: 335-8.

42. Geurts L, Neyrinck AM, Delzenne NM, Knauf C, Cani PD. Gut microbiota controls adipose tissue expansion, gut barrier and glucose metabolism: novel insights into molecular targets and interventions using prebiotics. Benef Microbes 2014;5:3-17.

43. Collins SM, Surette M, Bercik P. The interplay between the intestinal microbiota and the brain. Nat Rev Microbiol 2012;10:735-42.

44. Gárate I, Garcia-Bueno B, Madrigal JL, et al. Stress-induced neuroinflammation: role of the toll-like receptor-4 pathway. Biol Psychiatry 2013;73: $32-43$.

45. Bereswill S, Kühl AA, Alutis M, et al. The impact of toll-like-receptor-9 on intestinal microbiota composition and extra-intestinal sequelae in experimental Toxoplasma gondii induced ileitis. Gut Pathog 2014;6:19.
46. de Zoete MR, Flavell RA. Interactions between Nod-like receptors and intestinal bacteria. Front Immunol 2013;4:462.

47. Elinav E, Henao-Mejia J, Flavell RA. Integrative inflammasome activity in the regulation of intestinal mucosal immune responses. Mucosal Immunol 2013;6:4-13.

48. Sun Y, Zhang M, Chen CC, et al. Stress-induced corticotropin-releasing hormone-mediated NLRP6 inflammasome inhibition and transmissible enteritis in mice. Gastroenterology 2013;144:1478-87, 1487.e1-8.

49. Hansen J, Gulati A, Sartor RB. The role of mucosal immunity and host genetics in defining intestinal commensal bacteria. Curr Opin Gastroenterol 2010;26:564-71.

50. Mattar AF, Teitelbaum DH, Drongowski RA, Yongyi F, Harmon CM, Coran AG. Probiotics up-regulate MUC-2 mucin gene expression in a Caco-2 cell-culture model. Pediatr Surg Int 2002;18:586-90.

51. Wrzosek L, Miquel S, Noordine ML, et al. Bacteroides thetaiotaomicron and Faecalibacterium prausnitzii influence the production of mucus glycans and the development of goblet cells in the colonic epithelium of a gnotobiotic model rodent. BMC Biol 2013;11:61.

52. Hooper LV, Stappenbeck TS, Hong CV, Gordon JI. Angiogenins: a new class of microbicidal proteins involved in innate immunity. Nat Immunol 2003;4:269-73.

53. Stappenbeck TS, Hooper LV, Gordon JI. Developmental regulation of intestinal angiogenesis by indigenous microbes via Paneth cells. Proc Natl Acad Sci USA 2002;99:15451-5.

54. Wadhawan R, Oh W, Hintz SR, et al. Neurodevelopmental outcomes of extremely low birth weight infants with spontaneous intestinal perforation or surgical necrotizing enterocolitis. J Perinatol 2014;34:64-70.

55. O'Shea TM. Cerebral palsy in very preterm infants: new epidemiological insights. Ment Retard Dev Disabil Res Rev 2002;8:135-45.

56. Aydemir C, Dilli D, Uras N, et al. Total oxidant status and oxidative stress are increased in infants with necrotizing enterocolitis. J Pediatr Surg 2011;46:2096-100.

57. Strocker AM, Snijders RJ, Carlson DE, et al. Fetal echogenic bowel: parameters to be considered in differential diagnosis. Ultrasound Obstet Gynecol 2000;16:519-23.

58. Garzoni L, Faure C, Frasch MG. Fetal cholinergic anti-inflammatory pathway and necrotizing enterocolitis: the brain-gut connection begins in utero. Front Integr Neurosci 2013;7:57.

59. Eschenbach DA. Ureaplasma urealyticum and premature birth. Clin Infect Dis 1993;17:Suppl 1:S100-6.

60. Okogbule-Wonodi AC, Gross GW, Sun CC, et al. Necrotizing enterocolitis is associated with ureaplasma colonization in preterm infants. Pediatr Res 2011;69(5 Pt 1):442-7.

61. Torrazza RM, Neu J. The altered gut microbiome and necrotizing enterocolitis. Clin Perinatol 2013;40:93-108.

62. Mai V, Young CM, Ukhanova M, et al. Fecal microbiota in premature infants prior to necrotizing enterocolitis. PLoS One 2011;6:e20647.

63. Madan JC, Salari RC, Saxena D, et al. Gut microbial colonisation in premature neonates predicts neonatal sepsis. Arch Dis Child Fetal Neonatal Ed 2012;97:F456-62.

64. Mai V, Torrazza RM, Ukhanova M, et al. Distortions in development of intestinal microbiota associated with late onset sepsis in preterm infants. PLoS One 2013;8:e52876.

65. Sherman MP, Minnerly J, Curtiss W, Rangwala S, Kelley ST. Research on neonatal microbiomes: what neonatologists need to know. Neonatology 2014;105:14-24.

66. Liu LW, Thuneberg L, Huizinga JD. Development of pacemaker activity and interstitial cells of Cajal in the neonatal mouse small intestine. Dev Dyn 1998;213:271-82.

67. Zuo DC, Choi S, Shahi PK, et al. Inhibition of pacemaker activity in interstitial cells of Cajal by LPS via NF- $\mathrm{KB}$ and MAP kinase. World J Gastroenterol 2013;19:1210-8.

68. Sykes L, MacIntyre DA, Yap XJ, Teoh TG, Bennett PR. The Th1:th2 dichotomy of pregnancy and preterm labour. Mediators Inflamm 2012;2012:967629. 


\section{Microbes and neonatal gut-brain axis}

69. Hoeman CM, Dhakal M, Zaghouani AA, et al. Developmental expression of IL-12R $\beta 2$ on murine naive neonatal T cells counters the upregulation of IL-13R $\alpha 1$ on primary Th1 cells and balances immunity in the newborn. J Immunol 2013;190:6155-63.

70. Dammann O, Leviton A. Role of the fetus in perinatal infection and neonatal brain damage. Curr Opin Pediatr 2000;12:99-104.

71. Murthy V, Kennea NL. Antenatal infection/inflammation and fetal tissue injury. Best Pract Res Clin Obstet Gynaecol 2007;21:479-89.

72. Leviton A, Paneth N, Reuss ML, et al. Maternal infection, fetal inflammatory response, and brain damage in very low birth weight infants. Developmental Epidemiology Network Investigators. Pediatr Res 1999;46:566-75.

73. Elovitz MA, Brown AG, Breen K, Anton L, Maubert M, Burd I. Intrauterine inflammation, insufficient to induce parturition, still evokes fetal and neonatal brain injury. Int J Dev Neurosci 2011;29:663-71.

74. Sehgal S, Ewing C, Waring P, Findlay R, Bean X, Taeusch HW. Morbidity of low-birthweight infants with intrauterine cocaine exposure. J Natl Med Assoc 1993;85:20-4.

75. Toyosaka A, Tomimoto Y, Nose K, Seki Y, Okamoto E. Immaturity of the myenteric plexus is the aetiology of meconium ileus without mucoviscidosis: a histopathologic study. Clin Auton Res 1994;4:175-84.

76. Kubota A, Imura $\mathrm{K}$, Yagi $\mathrm{M}$, et al. Functional ileus in neonates: Hirschsprung's disease-allied disorders versus meconium-related ileus. Eur J Pediatr Surg 1999;9:392-5.

77. Ohuoba E, Fruhman G, Olutoye O, Zacharias N. Perinatal survival of a fetus with intestinal volvulus and intussusception: a case report and review of the literature. AJP Rep 2013;3:107-12.

78. Merhar SL, Ramos Y, Meinzen-Derr J, Kline-Fath BM. Brain magnetic resonance imaging in infants with surgical necrotizing enterocolitis or spontaneous intestinal perforation versus medical necrotizing enterocolitis. J Pediatr 2014;164:410-2.e1.

79. Zhou Y, Yang J, Watkins DJ, et al. Enteric nervous system abnormalities are present in human necrotizing enterocolitis: potential neurotransplantation therapy. Stem Cell Res Ther 2013;4:157.

80. Parikh NA, Lasky RE, Kennedy KA, McDavid G, Tyson JE. Perinatal factors and regional brain volume abnormalities at term in a cohort of extremely low birth weight infants. PLoS One 2013;8:e62804.

81. Filan PM, Hunt RW, Anderson PJ, Doyle LW, Inder TE. Neurologic outcomes in very preterm infants undergoing surgery. J Pediatr 2012;160:40914.

82. Fernandez EF, Watterberg KL. Relative adrenal insufficiency in the preterm and term infant. J Perinatol 2009;29:Suppl 2:S44-9.

83. Perkin GD, Murray-Lyon I. Neurology and the gastrointestinal system. J Neurol Neurosurg Psychiatry 1998;65:291-300.

84. Li Y, Gonzalez P, Zhang L. Fetal stress and programming of hypoxic/ischemic-sensitive phenotype in the neonatal brain: mechanisms and possible interventions. Prog Neurobiol 2012;98:145-65.

85. Diaz Heijtz R, Wang S, Anuar F, et al. Normal gut microbiota modulates brain development and behavior. Proc Natl Acad Sci USA 2011;108: 3047-52.

86. Douglas-Escobar M, Elizabeth Elliott E, Josef Neu J. Effect of intestinal microbial ecology on the developing brain. JAMA Pediatr 2013;167: 374-9.

87. Underwood MA. Human milk for the premature infant. Pediatr Clin North Am 2013;60:189-207.

88. Rollo DE, Radmacher PG, Turcu RM, Myers SR, Adamkin DH. Stability of lactoferrin in stored human milk. J Perinatol 2014;34:284-6.
89. Christen L, Lai CT, Hartmann B, Hartmann PE, Geddes DT. The effect of UV-C pasteurization on bacteriostatic properties and immunological proteins of donor human milk. PLoS One 2013;8:e85867.

90. Sherman MP, Miller MM, Sherman J, Niklas V. Lactoferrin and necrotizing enterocolitis. Curr Opin Pediatr 2014;26:146-50.

91. Jantscher-Krenn E, Zherebtsov M, Nissan C, et al. The human milk oligosaccharide disialyllacto- $\mathrm{N}$-tetraose prevents necrotising enterocolitis in neonatal rats. Gut 2012;61:1417-25.

92. De Plaen IG. Inflammatory signaling in necrotizing enterocolitis. Clin Perinatol 2013;40:109-24.

93. Chassard C, de Wouters T, Lacroix C. Probiotics tailored to the infant: a window of opportunity. Curr Opin Biotechnol 2014;26:141-7.

94. Marx C, Bridge R, Wolf AK, Rich W, Kim JH, Bode L. Human milk oligosaccharide composition differs between donor milk and mother's own milk in the NICU. J Hum Lact 2014;30:54-61.

95. Friel JK, Diehl-Jones B, Cockell KA, et al. Evidence of oxidative stress in relation to feeding type during early life in premature infants. Pediatr Res 2011;69:160-4.

96. Penn AH, Altshuler AE, Small JW, Taylor SF, Dobkins KR, Schmid-Schönbein GW. Digested formula but not digested fresh human milk causes death of intestinal cells in vitro: implications for necrotizing enterocolitis. Pediatr Res 2012;72:560-7.

97. Grenham S, Clarke G, Cryan JF, Dinan TG. Brain-gut-microbe communication in health and disease. Front Physiol 2011;2:94.

98. Galley JD, Bailey MT. Impact of stressor exposure on the interplay between commensal microbiota and host inflammation. Gut Microbes 2014;5: $390-6$.

99. Tarnow-Mordi W, Soll RF. Probiotic supplementation in preterm infants: it is time to change practice. J Pediatr 2014;164:959-60.

100. Shiou SR, Yu Y, Guo Y, et al. Synergistic protection of combined probiotic conditioned media against neonatal necrotizing enterocolitis-like intestinal injury. PLoS One 2013;8:e65108.

101. Jacobi SK, Odle J. Nutritional factors influencing intestinal health of the neonate. Adv Nutr 2012;3:687-96.

102. Kuzniewicz MW, Wi S, Qian Y, Walsh EM, Armstrong MA, Croen LA. Prevalence and neonatal factors associated with autism spectrum disorders in preterm infants. J Pediatr 2014;164:20-5.

103. Hsiao EY, McBride SW, Hsien S, et al. Microbiota modulate behavioral and physiological abnormalities associated with neurodevelopmental disorders. Cell 2013;155:1451-63.

104. Cohen-Poradosu R, McLoughlin RM, Lee JC, Kasper DL. Bacteroides fragilis-stimulated interleukin-10 contains expanding disease. J Infect Dis 2011;204:363-71.

105. Elitt CM, Rosenberg PA. The challenge of understanding cerebral white matter injury in the premature infant. Neuroscience 2014;276:216-38.

106. Panigrahy A, Wisnowski JL, Furtado A, Lepore N, Paquette L, Bluml S. Neuroimaging biomarkers of preterm brain injury: toward developing the preterm connectome. Pediatr Radiol 2012;42:Suppl 1:S33-61.

107. Englander ZA, Pizoli CE, Batrachenko A, et al. Diffuse reduction of white matter connectivity in cerebral palsy with specific vulnerability of long range fiber tracts. Neuroimage Clin 2013;2:440-7.

108. Tillisch K, Labus JS. Advances in imaging the brain-gut axis: functional gastrointestinal disorders. Gastroenterology 2011;140:407-411.e1.

109. Borre YE, O’Keeffe GW, Clarke G, Stanton C, Dinan TG, Cryan JF. Microbiota and neurodevelopmental windows: implications for brain disorders. Trends Mol Med Trends Mol Med 2014;20:509-18. 